Gut, 1973, 14, 348-353

\title{
Bile acids in the diarrhoea of ileal resection
}

\author{
W. D. Mitchell, J. M. Findlay, R. J. PRESCOTT, M. A. EASTWOOd, \\ AND D. B. HORN \\ From the Wolfson Gastro-Intestinal Laboratories, Western General Hospital, Department of Medicine, \\ University of Edinburgh, Edinburgh
}

SUMMARY Twenty individual diarrhoeal stools from three patients with ileal resection were centrifuged at $14000 \mathrm{~g}$ for one hour at $10^{\circ} \mathrm{C}$ to separate the stool into pellet and supernatant. Bile acids and electrolytes were measured in each phase.

Relationships were examined between chenodeoxycholic acid and cholic acid in each phase and in toto to electrolyte and water loss.

Chenodeoxycholic acid was associated with electrolyte and water loss whether present in solid or liquid phase. The association varied between individuals. The cholic acid content of the stool showed no association with electrolyte and water loss. It would appear that it is the total amount of chenodeoxycholic acid entering the colon, irrespective of its physical state, that is important in the diarrhoea of ileal dysfunction.

When the enterohepatic circulation of bile acids is broken, due to ileal disease or resection, excessive quantities of bile acids enter the colon and watery diarrhoea may occur (Hofmann, 1967).

In 1966 Forth, Rummel, and Glasner demonstrated that bile acids inhibited electrolyte and water reabsorption in the rat colon. Perfusion of the human colon with conjugated bile acids has been shown to cause secretion of water and electrolytes (Mekhjian, Phillips, and Hofmann, 1968). Similarly, perfusion of both the canine and human colon with unconjugated bile acids inhibited electrolyte and water reabsorption (Mekhjian and Phillips, 1970; Mekhjian, Phillips, and Hofmann, 1971). The unconjugated dihydroxy bile acids, deoxycholic acid, and chenodeoxycholic acid were found to be the most potent inhibitors of electrolyte and water absorption in the colon. The study by Mitchell and Eastwood (1972) showed that in patients with diarrhoea associated with ileal dysfunction chenodeoxycholic acid and cholic acid, but not deoxycholic acid, were excreted in the faeces.

Although treatment of the diarrhoea with sequestrating agents such as cholestyramine (Hofmann and Poley, 1969) and lignin (Eastwood and Girdwood, 1968) is often successful, the amount of bile acids excreted remains the same or may even increase (Hofmann and Poley, 1972). There would appear to be an anomaly here, suggesting that the

Received for publication 2 March 1973. physical state of bile acids is important in the genesis of watery diarrhoea. Norman (1964) has shown that bile acids adhere strongly to insoluble materials in normal stool. A hypothesis has been examined that bile acids in solution have a biological effect, whereas bile acids adsorbed to insoluble materials would be biologically inert.

For these reasons the present study was undertaken to examine the relationship between chenodeoxycholic acid, cholic acid in solution or bound to stool-insoluble materials, and both the electrolyte and the water loss in the faeces of patients with diarrhoea associated with ileal resection.

\section{Materials and Methods}

The patients studied were outpatients on an unrestricted diet. Their clinical details are summarized in table I. They had had resections of varying lengths of terminal ileum. The bile acid and electrolyte contents of each stool specimen were measured.

FAECAL ANALYSIS

Sequential individuals' stools were collected free from urine, each motion being weighed and then stored at $-20^{\circ} \mathrm{C}$ until analysed. Before analysis the collections were thawed and homogenized but no water was added. The bile acid and electrolyte content of the aqueous fraction of the stool was analysed using the supernatant produced by centrifugation of an aliquot of the homogenized faeces at 


\begin{tabular}{|c|c|c|c|c|}
\hline Subject & $\operatorname{Sex}$ & Indication for Resection (resection in $\mathrm{cm}$ ) & $\begin{array}{l}\text { Schilling Test with } \\
\text { Intrinsic Factor } \\
\text { (normal }>16)\end{array}$ & Faecal Fat $(g / 24 \mathrm{hr})$ \\
\hline G (54 yr) & $\mathbf{F}$ & $\begin{array}{l}\text { Crohn's disease } \\
\text { (95 cm distal ileum) } \\
\text { ( } 20 \mathrm{~cm} \text { ascending colon) }\end{array}$ & $7 \cdot 5$ & $9 \cdot 9$ \\
\hline McK (44 yr) & $\mathbf{M}$ & Crohn's disease & $6 \cdot 3$ & $8 \cdot 8$ \\
\hline
\end{tabular}

Table I Clinical details of patients studied

$14000 \mathrm{~g}$ for 60 minutes (Findlay, Eastwood, and Mitchell, 1973).

\section{FAECAL BILE ACIDS}

The pellet and supernatant so produced were freezedried before quantitative faecal bile acid analyses according to the method of Evrard and Janssen (1968) in which the bile acids are converted to ketones. One slight modification was the use of a $3 \%$ OV-17 Gas Chrom Q 100-120 mesh column being used isothermally at $270^{\circ} \mathrm{C}$. Standards lithocholic acid $1 \mathrm{mg} / \mathrm{ml}$, deoxycholic acid $1 \mathrm{mg} / \mathrm{ml}, 23-$ nordeoxycholic acid $1 \mathrm{mg} / \mathrm{ml}$, and cholic acid 2 $\mathrm{mg} / \mathrm{ml}$ were analysed through the whole procedure and all samples were analysed in duplicate. Recovery from faecal samples of added cholic acid was $98 \%$ and of chenodeoxycholic acid was $98 \%(n=4)$. The coefficient of variation of replicate analysis $(n=16)$, carried out during the experimental period of a standard mixture, was $7.7 \%$ for monoketo acids, $5 \cdot 6 \%$ for diketo acids, and $8 \cdot 5 \%$ for triketo acids.

FAECAL ELECTROLYTES

The concentrations of sodium and potassium in the stools were measured using a standard AutoAnalyzer technique. Pellet electrolytes were estimated after digestion of organic material with concentrated nitric acid (Analar).

\section{STATISTICAL ANALYSIS}

In the statistical analysis all variables described have been standardized by division by the associated pellet weight in order to ensure that any associations found between variables could not be due simply to a mutual association with the weight of stool collected on various occasions.

The first two stages of analysis have been to relate first the electrolyte and then the water loss to the total amount of chenodeoxycholic acid and the total amount of cholic acid present in the faeces. Multiple regression techniques were used (see for example Armitage, 1971).
Subsequently the relationship of electrolyte or water loss to the bile acids was further examined. Separate consideration was given to the role of the pellet and supernatant fractions of either cholic or chenodeoxycholic acid, again using multiple regression techniques.

\section{Results}

The individual stool weights, bile acids, and electrolytes in the individual faecal samples are shown in table II. Only 3.7-diketocholanoic and 3, 7, 12triketocholanoic acids were obtained.

TOTAL BILE ACIDS AND ELECTROLYTE LOSS Assuming that electrolyte loss (Y) is linearly dependent on the total cholic $(C)$ and total chenodeoxycholic acid (CDC) we have: $Y=a+b_{1} C+b_{2} C D C$ where $b_{1}$ and $b_{2}$ are the partial regression coefficients of electrolyte loss on cholic and chenodeoxycholic acids respectively and represent the increase observed in electrolyte loss for an increase of one unit in the amount of either bile acid present. The constant ' $a$ ' is a measure of the individual's ability to tolerate bile acids without incurring abnormal electrolyte loss.

Standard methods of multiple regression were applied to the faecal collections to compare these constants. Table III and the figure show that the value of ' $a$ ' differs significantly between individuals $(P<0.01)$. There is no significant difference in the values of the partial regression coefficients $\left(b_{1}\right.$ and $\left.b_{2}\right)$ between individuals. These findings were used in the subsequent analysis where different values have been allowed for ' $a$ '. The pooled estimates of the regression coefficients $b_{1}$ and $b_{2}$ have been compared with one another to see whether either of the two bile acids is more closely associated with electrolyte loss. The estimates of $b_{1}$ and $b_{2}$ with their standard errors are 0.005 $( \pm 0.005)$ and 0.031 $( \pm 0.004)$ respectively. Thus $b_{2}$ differs significantly from zero $(P<0.001)$ and from $b_{1}(P<0.01) ; b_{1}$ does not differ significantly from zero $(P>0 \cdot 2)$. 


\begin{tabular}{|c|c|c|c|c|c|c|c|c|c|c|}
\hline \multirow[t]{2}{*}{ Subject } & \multicolumn{2}{|c|}{ Faecal Weight $(g)$} & \multicolumn{4}{|c|}{ Faecal Bile Acids (mg) } & \multicolumn{4}{|c|}{ Total Faecal Electrolytes (m/equiv) } \\
\hline & Pellet & $\begin{array}{l}\text { Super- } \\
\text { natant }\end{array}$ & \multicolumn{2}{|l|}{ Pellet } & \multicolumn{2}{|c|}{ Supernatant } & \multicolumn{2}{|c|}{ Supernatant } & \multicolumn{2}{|c|}{ Pellet } \\
\hline $\mathbf{G}$ & $\begin{array}{r}159.0 \\
33.4 \\
124.0 \\
20.3 \\
5.4 \\
158 \cdot 2 \\
40.0 \\
80.7 \\
44.2 \\
62.3 \\
173.0\end{array}$ & $\begin{array}{r}165.0 \\
45.6 \\
154.0 \\
84.7 \\
8.6 \\
189.8 \\
105.0 \\
291.3 \\
29.8 \\
0.7 \\
180.0\end{array}$ & $\begin{array}{r}1285 \cdot 5 \\
297 \cdot 6 \\
1647 \cdot 8 \\
364 \cdot 4 \\
40.9 \\
1105 \cdot 8 \\
350 \cdot 8 \\
741 \cdot 6 \\
326 \cdot 2 \\
267.0 \\
1435.0\end{array}$ & $\begin{array}{r}1943 \cdot 0 \\
313 \cdot 4 \\
2335 \cdot 1 \\
214 \cdot 0 \\
29 \cdot 2 \\
1292 \cdot 5 \\
311 \cdot 2 \\
1055 \cdot 6 \\
470 \cdot 5 \\
539 \cdot 8 \\
1920 \cdot 3\end{array}$ & $\begin{array}{r}141.9 \\
10.6 \\
97.0 \\
13.6 \\
14.8 \\
87.3 \\
42.0 \\
113.7 \\
22.1 \\
0.0 \\
66.2\end{array}$ & $\begin{array}{r}290.4 \\
118 \cdot 1 \\
218 \cdot 6 \\
33.0 \\
8.7 \\
510 \cdot 6 \\
179.6 \\
716.6 \\
105 \cdot 5 \\
0.0 \\
180.8\end{array}$ & $\begin{array}{r}7 \cdot 9 \\
2.7 \\
6 \cdot 8 \\
6 \cdot 5 \\
0.2 \\
10.1 \\
8 \cdot 8 \\
12 \cdot 2 \\
1 \cdot 0 \\
0.0 \\
9.0\end{array}$ & $\begin{array}{r}9 \cdot 1 \\
2 \cdot 3 \\
10.0 \\
2 \cdot 4 \\
0.6 \\
6.3 \\
2.9 \\
11 \cdot 4 \\
2 \cdot 3 \\
0.0 \\
8 \cdot 1\end{array}$ & $\begin{array}{l}7.6 \\
2.0 \\
5.5 \\
1.6 \\
0.1 \\
8.4 \\
3.4 \\
3.4 \\
1.5 \\
0.1 \\
8.7\end{array}$ & $\begin{array}{l}8.8 \\
1.7 \\
8.1 \\
0.6 \\
0.4 \\
5.3 \\
1.1 \\
3.2 \\
3.4 \\
0.0 \\
7.8\end{array}$ \\
\hline McK & $\begin{array}{r}51 \cdot 0 \\
44.9 \\
153.0 \\
151.9 \\
81 \cdot 3 \\
64.7\end{array}$ & $\begin{array}{r}214.0 \\
65.0 \\
197.0 \\
230.0 \\
75.0 \\
127.0\end{array}$ & $\begin{array}{l}612 \cdot 2 \\
501 \cdot 0 \\
814 \cdot 8 \\
894 \cdot 7 \\
364 \cdot 2 \\
415 \cdot 9\end{array}$ & $\begin{array}{r}613 \cdot 3 \\
412 \cdot 4 \\
1036 \cdot 8 \\
1336 \cdot 8 \\
559 \cdot 2 \\
471 \cdot 5\end{array}$ & $\begin{array}{r}15 \cdot 0 \\
3 \cdot 3 \\
19 \cdot 7 \\
18 \cdot 4 \\
4 \cdot 5 \\
11 \cdot 4\end{array}$ & $\begin{array}{r}64 \cdot 2 \\
41 \cdot 6 \\
309 \cdot 3 \\
248 \cdot 4 \\
72 \cdot 8 \\
58 \cdot 4\end{array}$ & $\begin{array}{r}15.4 \\
6 \cdot 2 \\
10.0 \\
9 \cdot 2 \\
2.5 \\
7.6\end{array}$ & $\begin{array}{l}4.9 \\
1 \cdot 8 \\
4 \cdot 5 \\
4 \cdot 6 \\
2.4 \\
3.6\end{array}$ & $\begin{array}{l}3 \cdot 7 \\
4 \cdot 3 \\
7 \cdot 8 \\
6 \cdot 1 \\
2 \cdot 7 \\
3 \cdot 9\end{array}$ & $\begin{array}{l}1 \cdot 2 \\
1 \cdot 2 \\
3 \cdot 5 \\
3 \cdot 0 \\
2.6 \\
1.8\end{array}$ \\
\hline $\mathbf{M}$ & $\begin{array}{r}15.0 \\
34.0 \\
20.0 \\
111.0\end{array}$ & $\begin{array}{l}65.0 \\
46.0 \\
24.0 \\
65.0\end{array}$ & $\begin{array}{r}68.9 \\
86 \cdot 7 \\
14 \cdot 4 \\
456 \cdot 2\end{array}$ & $\begin{array}{r}69 \cdot 6 \\
157 \cdot 1 \\
77 \cdot 4 \\
690 \cdot 4\end{array}$ & $\begin{array}{r}228 \cdot 0 \\
17 \cdot 3 \\
0.8 \\
37 \cdot 0\end{array}$ & $\begin{array}{r}176.0 \\
68.0 \\
14.9 \\
156.0\end{array}$ & $\begin{array}{l}5 \cdot 2 \\
1 \cdot 7 \\
0 \cdot 2 \\
3 \cdot 0\end{array}$ & $\begin{array}{l}3 \cdot 6 \\
2 \cdot 5 \\
1 \cdot 1 \\
2 \cdot 4\end{array}$ & $\begin{array}{l}1 \cdot 2 \\
1 \cdot 3 \\
0 \cdot 2 \\
5 \cdot 1\end{array}$ & $\begin{array}{l}0.8 \\
1.8 \\
0.9 \\
4.1\end{array}$ \\
\hline
\end{tabular}

Table II Results in individual stool weights

${ }^{1} \mathrm{CDC}$ represents those faecal bile acids substituted in positions 3 and 7

${ }^{2} \mathrm{C}$ represents those faecal bile acids substituted in positions 3,7 , and 12 .

TOTAL BILE ACIDS AND WATER LOSS

The analysis followed precisely the same procedure as was adopted for examining electrolyte loss and total bile acids with the substitution of water loss for electrolyte loss. No significant differences were found between patients in the values of $b_{1}$ and $b_{2}$ while the values of ' $a$ ' were found to differ only at the $10 \%$ level of significance (table IV): $b_{2}(0 \cdot 191 \pm 0 \cdot 049)$ was again found to differ significantly from zero $(\mathrm{P}<0.01)$ while $\mathrm{b}_{1}(0.075 \pm 0.063)$ did not $(\mathrm{P}>$ $0 \cdot 2)$.

\section{ELECTROLYTE LOSS AND THE DISTRIBUTION OF BILE ACIDS IN THE SUPERNATANT AND PELLET}

The equation applied to examine the association of electrolyte loss with the distribution of bile acids in the supernatant and pellet was

$$
Y=a+b_{1}^{\prime} X_{1}+b_{2}{ }^{\prime} X_{2}+b_{3}{ }^{\prime} X_{3}+b_{4}{ }^{\prime} X_{4}
$$

where ' $a$ ' could vary between individuals and

$X_{1}=$ cholic acid in pellet $(\mathrm{mg})$

$\mathrm{X}_{2}=$ chenodeoxycholic acid in pellet $(\mathrm{mg})$

$\mathrm{X}_{3}=$ cholic acid in supernatant $(\mathrm{mg})$

$\mathrm{X}_{\mathbf{4}}=$ chenodeoxycholic acid in supernatant (mg)

$b_{1}{ }^{\prime}, b_{2}{ }^{\prime} b_{3}{ }^{\prime}, b_{4}{ }^{\prime}$ are partial regression coefficients.

Employing the findings of the previous sections it was assumed that a similar pattern would hold for the individual fractions in pellet and supernatant and that $b_{1}{ }^{\prime}, b_{2}{ }^{\prime}, b_{3}{ }^{\prime}$, and $b_{4}{ }^{\prime}$ would remain constant for all three patients although ' $a$ ' would differ. The data were not sufficiently extensive to test this

\begin{tabular}{|c|c|c|c|c|c|}
\hline Source of Variation & Degrees of Freedom & Sums of Squares & Mean Square & Variance Ratio & Level of Significance \\
\hline \multicolumn{6}{|c|}{ Analysis of Variance for Differences between Partial Regression Coefficients $\left(b_{1}\right.$ and $\left.b_{2}\right)$} \\
\hline $\begin{array}{l}\text { Regression with common } \\
b_{1} \text { and } b_{2}\end{array}$ & 2 & 0.4489 & 0.2244 & 53.4 & $P<0.01$ \\
\hline \multirow{2}{*}{$\begin{array}{l}b_{1} \text { and } b_{2} \\
\text { Difference in } b_{1} \text { and } b_{2} \\
\text { between individuals } \\
\text { Residual about separate } \\
\text { regressions }\end{array}$} & 4 & 0.0058 & 0.0014 & \multirow[t]{2}{*}{$<1$} & \multirow[t]{2}{*}{ Not significant } \\
\hline & 12 & 0.0509 & 0.0042 & & \\
\hline \multicolumn{6}{|c|}{$\begin{array}{lccc}\text { Analysis of Covariance for Differences between the 'a's (Assuming Common } b_{1} \text { and } b_{2} \text { ) } \\
\text { Between individuals } & 2 & 0.0740 & 0.0370 \\
\text { Within individuals } & 16 & 0.0567 & 0.0035\end{array}$} \\
\hline
\end{tabular}

Table III Comparison among three individuals of multiple regressions of electrolyte loss on total cholic and total chenodeoxycholic acids 


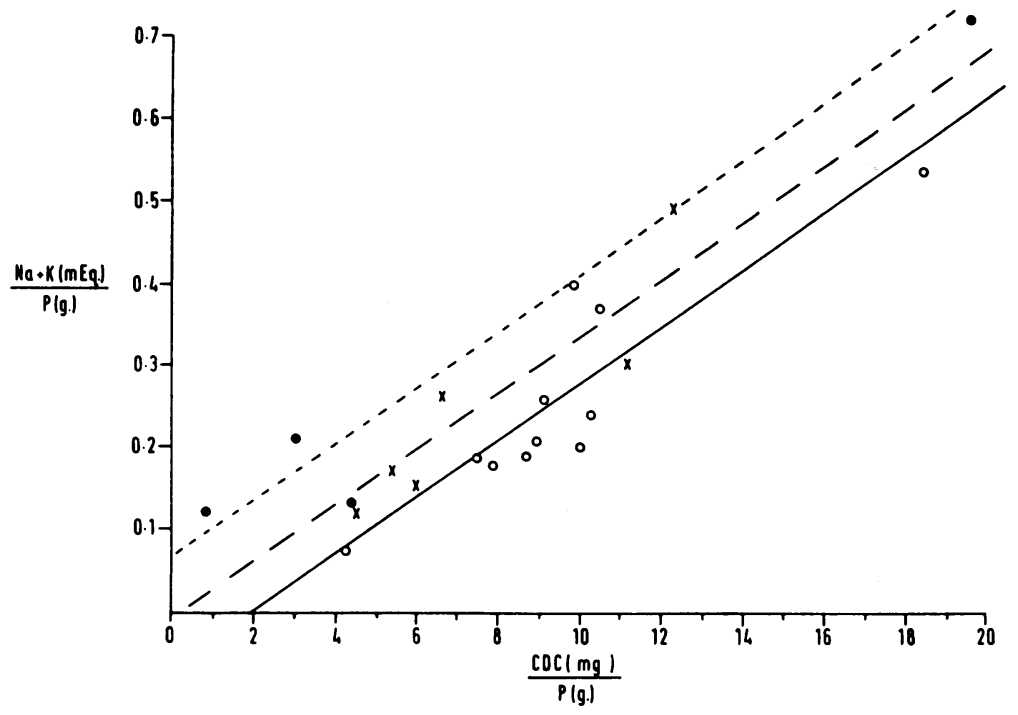

Fig Regression lines for the three patients studied.

G..., McM ... x, M....

$$
\begin{gathered}
\frac{C D C}{P}=\frac{\text { Total chenodeoxycholic acid }(\mathrm{mg}) \text { excreted in each faecal sample }}{\text { Weight of pellet }(\mathrm{g}) \text { in that faecal sample }} \\
\frac{N a+K}{P}=\frac{\text { Total sodium }(\mathrm{Na}) \text { plus potassium }(\mathrm{K})(\mathrm{m} \text {-equiv) in each faecal sample }}{\text { Weight of pellet }(\mathrm{g}) \text { in that faecal sample }}
\end{gathered}
$$

assumption independently. Standard multiple regression methods were applied to determine the pooled values of $b_{1}{ }^{\prime}, b_{2}{ }^{\prime}, b_{3}{ }^{\prime}, b_{4}{ }^{\prime}$.

Table $\mathrm{V}$ shows their values together with their standard errors. The chenodeoxycholic acid in the pellet is the component most closely associated with electrolyte loss but inspection of the standard errors show that this coefficient $b_{2}^{\prime}$ does not differ significantly from either $b_{3}{ }^{\prime}$ and $b_{4}{ }^{\prime}$. $b_{1}{ }^{\prime}$ did not differ significantly from zero. Thus every fraction except cholic acid in the pellet was associated with electrolyte loss.
WATER LOSS AND THE DISTRIBUTION OF BILE ACIDS IN THE SUPERNATANT AND PELLET

Following a similar analysis to that employed for electrolyte loss corresponding estimates of $b_{1}{ }^{\prime}, b_{2}{ }^{\prime}$, $b_{3}{ }^{\prime}$, and $b_{4}{ }^{\prime}$ with their standard errors were obtained and are shown in table $V$. The findings are in general agreement with those obtained for electrolyte loss. Chenodeoxycholic acid again seems to have the greater effect on diarrhoea when present in the pellet fraction with the contribution from the supernatant

\begin{tabular}{|c|c|c|c|c|c|}
\hline Source of Variation & Degrees of Freedom & Sums of Squares & Mean Square & Variance Ratio & Level of Significance \\
\hline \multicolumn{6}{|c|}{ Analysis of Variance for Differences between Partial Regression Coefficients $\left(b_{1}\right.$ and $\left.b_{2}\right)$} \\
\hline $\begin{array}{l}\text { Regression with common } \\
b_{1} \text { and } b_{9}\end{array}$ & 2 & $21 \cdot 80$ & 10.90 & $22 \cdot 4$ & $P<-0.01$ \\
\hline $\begin{array}{l}\text { Difference in } b_{1} \text { and } b_{2} \\
\text { between individuals }\end{array}$ & 4 & $4 \cdot 17$ & 1.04 & $2 \cdot 1$ & Not significant \\
\hline $\begin{array}{l}\text { Residual about separate } \\
\text { regressions }\end{array}$ & 12 & $4 \cdot 83$ & 0.49 & & \\
\hline $\begin{array}{l}\text { Between individuals } \\
\text { Within individuals }\end{array}$ & $\begin{array}{r}2 \\
16\end{array}$ & $\begin{array}{r}3 \cdot 38 \\
10 \cdot 01\end{array}$ & $\begin{array}{l}1.69 \\
0.63\end{array}$ & $2 \cdot 7$ & Not significant \\
\hline
\end{tabular}
fraction not being statistically significant. Again

Table IV Comparison among three individuals of multiple regressions of water loss on total cholic and total chenodeoxycholic acids 


\begin{tabular}{|c|c|c|}
\hline & \multicolumn{2}{|c|}{ Partial Regression Coefficients $( \pm S E)$} \\
\hline & Electrolyte Loss & Water Loss \\
\hline $\begin{array}{l}b_{1}\left(C^{1} \text { in pellet) }\right. \\
b_{2}\left(C D C^{2} \text { in pellet) }\right. \\
b_{3} \text { (C in supernatant) } \\
b_{1}(C D C \text { in supernatant })\end{array}$ & $\begin{array}{c}-0.007( \pm 0.007) \\
0.035( \pm 0.005)^{8} \\
0.020( \pm 0.008)^{4} \\
0.019( \pm 0.007)^{4}\end{array}$ & $\begin{array}{r}-0.067( \pm 0.085) \\
0.284( \pm 0.057)^{3} \\
0.275( \pm 0.093)^{4} \\
-0.004( \pm 0.085)\end{array}$ \\
\hline
\end{tabular}

Table V Pooled partial regression coefficients from multiple regressions of electrolyte loss or water loss on cholic and chenodeoxycholic acids in supernatant and pellet

Levels of significance, ${ }^{1} \mathrm{C}$ represents cholic acid, ${ }^{2} \mathrm{CDC}$ represents chenodeoxycholic acid, ${ }^{3} \mathrm{P}<0.001,{ }^{4} \mathrm{P}<0.05$.

cholic acid in the pellet was not associated with water loss.

\section{Discussion}

We have shown that in each of the three patients studied there was a linear relationship between the amount of chenodeoxycholic acid excreted and electrolyte loss which was characteristic for each individual (see fig). We feel that the individual linear relationship demonstrated by the patients in our study is to be anticipated in view of the uniqueness of each subject's gastrointestinal tract.

Chenodeoxycholic acid is associated with water and electrolyte loss whether present in the pellet (concentration range $\mathbf{9} \cdot 0-21.8 \mathrm{mM}$ ) or supernatant (concentration range $0 \cdot 2-3.5 \mathrm{mM}$ ) but more particularly with the pellet fraction. Cholic acid in the pellet appears to have no effect on the diarrhoea despite concentrations in the pellet of between 14 and $30 \mathrm{mM}$. Cholic acid in the supernatant (concentration range $2 \cdot 2-5 \cdot 2 \mathrm{mM}$ ) has a statistically significant relationship with water and electrolyte loss.

The association of cholic acid with electrolyte and water loss would appear to conflict with previous reports that cholic acid in solution has no effect on inhibiting electrolyte and water reabsorption (Mekhjian and Phillips, 1970; Mekhjian et al, 1971). However it can be postulated that the association between cholic acid and water loss is a reflection of the solubility of cholic acid. The more water produced by the inhibitory property of chenodeoxycholic acid, the more cholic acid will be dissolved in this free water. In support of this postulate is the finding that total cholic acid, ie, cholic acid present in supernatant and pellet, did not reach a statistically significant level of association with either electrolyte or water loss once its association with chenodeoxycholic acid and pellet weight were taken into account. These findings are in agreement with perfusion studies in man (Mekhjian et al, 1971).

Total chenodeoxycholic acid, however, has been shown to be significantly associated with electrolyte and water loss even when its association with cholic acid and pellet weight was taken into account. The stronger of the two relationships was between chenodeoxycholic acid and electrolyte loss, suggesting that water loss is secondary to inhibition of electrolyte reabsorption.

Previous studies (Woodbury and Kern, 1971) attempted to associate faecal bile acid excretion and faecal water without removing the effect of the mutual association with the solid component of the stool. The associations these workers produced were not surprising as one would expect a sample of high weight to contain both more bile acids, and in the absence of any material change in the nature of the diarrhoea, more water. In the study of Woodbury and Kern (1971) it would appear that the water excreted in the faeces is a direct result of increased faecal bile acid excretion. Our results suggest that water loss is a secondary effect and is due to the inhibition of electrolyte reabsorption by excess bile acids being present in the colon.

In normal faeces, bile acids are present in a concentration of approximately $3 \mathrm{mM}$. Mekhjian et al (1971) showed that a $3 \mathrm{mM}$ solution of deoxycholic acid inhibited electrolyte and water reabsorption in the human colon. Norman (1964) showed that in normals faecal bile acids are strongly adsorbed to solids. This suggests that such adsorption renders the bile acids biologically inert. Our findings in the patients with diarrhoea due to ileal resection do not appear to support this hypothesis as the chenodeoxycholic acid in the pellet had a statistically significant association with electrolyte and water loss.

At the present time the mechanism by which bile acids inhibit electrolyte and water reabsorption and the relationship between their chemical structure and their effects is not known. Mekhjian et al (1971) suggested that bile acids may impair active sodium transport in the colon by altering enzyme configuration, by interfering with the binding of phosphate, or by altering lipid-protein interactions at cell membranes.

Unconjugated deoxycholic acid and chenodeoxycholic acid have been shown to cause slight structural 
changes in hamster and rat jejunal mucosa at concentrations of 1 to $5 \mathrm{mM}$ (Low-Beer, Schneider, and Dobbins, 1970; Teem and Phillips, 1972). It is interesting that these bile acids, which caused the structural changes in the small intestinal mucosa, are not normally present in the small intestine. Whilst we have not looked for any structural changes in the colon of our patients, it may well be that we have an analagous situation, ie, a high concentration of a bile acid not normally found in the colon causing ultrastructural changes in the colon.

Although our study does not allow us to suggest how the bile acids cause an increase in faecal excretion of electrolyte and water, it does indicate that chenodeoxycholic is probably the causative factor in the diarrhoea of patients with ileal resection.

The centrifugation technique used (Findlay et al, 1973) has led to a clearer understanding of the role of bile acids in the diarrhoea associated with ileal resection. However, even with this technique it is not possible to know whether the distribution of bile acids in the pellet and supernatant fractions found at faecal analysis correspond to those present at the sites of water and electrolyte absorption in the colon. It would appear that it is the total amount of chenodeoxycholic acid entering the colon, irrespective of its physical state, that is important in the diarrhoea of ileal dysfunction. Cholic acid on the other hand does not appear to have such a cathartic effect.

The authors wish to thank Miss Rhoda Anderson for her technical assistance and Drs Sircus and McManus for permission to study their patients. We would also like to thank Mrs Anne Jenkinson for secretarial help.

\section{References}

Armitage, P. (1971). Statistical Methods in Medical Research, p. 320. Blackwell, Oxford and Edinburgh.

Eastwood, M. A., and Girdwood, R. H. (1968). Lignin: a bile-salt sequestrating agent. Lancet, 2, 1170-1172.

Evrard, E., and Janssen, G. (1968). Gas-liquid chromatographic determination of human fecal bile acids. J. Lipid Res., 9, 226-236.

Findlay, J. M., Eastwood, M. A., and Mitchell, W. D. (1973). The physical state of bile acids in the diarrhoeal stool of ileal dysfunction. Gut, 14, 319-325.

Forth, W., Rummel, W., and Glasner, H. (1966). Zur resorptionshemmenden Wirkung von Gallensauren. Naunyn-Schmiedeberg's Arch. exp. Path. Pharmak., 254, 364-380.

Hofmann, A. F. (1967). The syndrome of ileal disease and the broken enterohepatic circulation: cholerheic enteropathy. Gastroenterology, 52, 752-757.

Hofmann, A. F., and Poley, J. R. (1969). Cholestyramine treatment of diarrhea associated with ileal resection. New Engl. J. Med., 281, 397-402.

Hofmann, A. F., and Poley, J. R. (1972). Role of bile acid malabsorption in pathogenesis of diarrhea and steatorrhea in patients with ileal resection. I. Response to cholestyramine or replacement of dietary long chain triglyceride by medium chain triglyceride. Gastroenterology, 62, 918-934.

Low-Beer, T. S., Schneider, R. E., and Dobbins, W. O. (1970). Morphological changes of the small-intestinal mucosa of guinea pig and hamster following incubation in vitro and perfusion in vivo with unconjugated bile salts. Gut, 11, 486492.

Mekhjian, H. S., and Phillips, S. F. (1970). Perfusion of the canine colon with unconjugated bile acids. Gastroenterology, 59, 120129.

Mekhjian, H. S., Phillips, S. F., and Hofmann, A. F. (1968). Conjugated bile salts block water and electrolyte transport by the human colon. (Abstr.) Gastroenterology, 54, 1256.

Mekhjian, H. S., Phillips, S. F., and Hofmann, A. F. (1971). Colonic secretion of water and electrolytes induced by bile acids: perfusion studies in man. J. clin. Invest., 50, 1569-1577.

Mitchell, W. D., and Eastwood, M. A. (1972). Faecal bile acids and neutral steroids in patients with ileal dysfunction. Scand. $J$. Gastroent., 7, 29-32.

Norman, A. (1964). Faecal excretion products of cholic acid in man. Brit. J. Nutr., 18, 173-186.

Teem, M. V., and Phillips, S. F. (1972). Perfusion of the hamster jejunum with conjugated and unconjugated bile acids: Inhibition of water absorption and effects on morphology. Gastroenterology, 62, 261-267.

Woodbury, J. F., and Kern, F., Jr. (1971). Fecal excretion of bile acids: a new technique for studying bile acid kinetics in patients with ileal resection. J. clin. Invest., 50, 2531-2540. 